\title{
¿Flexibilizando el nomos?: globalización y soberanía en la era del terror
}

\author{
Eduardo Hernando Nieto*
}

\section{Resumen}

Los hechos ocurridos en Ecuador con el bombardeo de la Fuerza Aérea Colombiana a una base de las FARC asentada en territorio ecuatoriano generaron una condena por parte de la mayoría de Estados en Latinoamérica. Sin embargo, tal hecho parecería contradictorio con relación a tesis como la de la globalización y flexibilización de las fronteras que estos mismos Estados defienden en otros contextos como por ejemplo el económico. En este sentido, se hace indispensable evaluar la posibilidad de llegar también a una flexibilización en el ámbito de la soberanía a fin de luchar eficazmente contra aquellas fuerzas que buscan precisamente aniquilar no solo la organización estatal sino peor aun la unidad política. Así como en la teoría legal existe la figura del "paternalismo jurídico», en donde paradójicamente se limita la voluntad individual a fin de salvaguardar la libertad personal, igualmente podría ser adecuado limitar temporalmente cierta forma de la soberanía estatal a fin de asegurar la unidad política todo esto dentro de un marco de excepcionalidad o emergencia.

* Profesor ordinario del Departamento de Derecho de la Pontificia Universidad Católica, adscrito al área de Teoría del Derecho. Doctor en Filosofía, Universidad Nacional Mayor de San Marcos. Master en Teoría Legal y Política, Universidad de East Anglia, Norwich-Inglaterra. 


\section{De la excepción "excepcional» a la excepción continua: El nuevo paradigma de la política contemporánea}

Así como lo resalta un autor tan comprometido con el problema de la excepción como Carl Schmitt, en su texto La dictadura ${ }^{1}$, la excepción es algo tan natural como la «normalidad», es más, podríamos agregar que porque existe la excepcionalidad tiene sentido hablar de normalidad, así como también porque existe excepción es posible hablar de norma ${ }^{2}$.

Sin embargo, en estos tiempos denominados postmodernos ${ }^{3}$ en los cuales parece que todo se mezcla y nada resulta claro parecería difícil mantener ya una distinción contundente entre estos dos conceptos, es decir, que hoy lo que era normal se transforma en excepcional y lo excepcional en normal, produciendo esto último una suerte de paradoja en la cual podría decirse que la excepción se mantiene de modo permanente.

Esto que parece un trabalenguas tiene sin embargo un sentido muy concreto en la realidad política que resulta bastante explosiva por decir lo menos. No solamente tenemos una discusión abierta respecto a la denominada "guerra contra el terrorismo» emprendida tras los atentados del 11 de septiembre de 2001 por los Estados Unidos sino también contamos a su vez con un intenso debate sobre lo que podría ser una novedosa teoría de la excepción ${ }^{4}$ o por otro lado, vemos también cómo se va desarrollando un discurso denominado "derecho penal del enemigo" que advierte a su vez sobre la naturaleza de la delincuencia de hoy y la manera más adecuada

1 Schmitt, Carl. La dictadura, desde los comienzos del pensamiento moderno de la soberanía hasta la lucha de clases proletarias. Madrid: Alianza, 1985

2 «La excepción es más interesante que el caso normal. Lo normal nada prueba; la excepción, todo; no solo confirma la regla, sino que esta vive en aquella». Schmitr, Carl. Teología política. Buenos Aires: Struhart \& Cia, 1998, p. 27.

3 Si la modernidad se definía en términos de centro que organiza la realidad a su alrededor la postmodernidad implica más bien la ausencia de referente o centro por lo tanto nada puede ser ordenado y todo queda indefinido.

4 Respecto a la teoría de la excepción obviamente el referente esencial sigue siendo la obra del constitucionalista y teórico político alemán Carl Schmitt, cfr., El concepto de lo político. Madrid: Alianza, 1991, además de los textos ya citados. Más recientemente se destaca el trabajo - aunque muy crítico de Schmitt- del filósofo italiano Giorgio Agamben, Estado de excepción, Buenos Aires: Adriano Hidalgo editores, 2004. Yo mismo he desarrollado toda esta perspectiva recientemente en el texto: "Derecho y Emergencia: Hacia una teoría del derecho enemigo». Lima: Departamento de Derecho de la PUCP, 2007. 
para combatirla5. Es más, el propio Schmitt en su texto La teoría del partisano, anunciaba también la nueva dinámica de los conflictos contemporáneos que ya en algunos casos podrían ser considerados como conflictos postmodernos ${ }^{6}$ enmarcados justamente dentro de una crisis quizá irreversible al interior del Estado moderno ${ }^{7}$.

En todos estos casos lo que se percibe es también una grave amenaza que se cierne sobre lo esencial para el desarrollo de la vida humana, vale decir, la unidad política y además un peligro para la continuidad de la comunidad civilizada que nos podría conducir hacia una restauración del estado de naturaleza de las tesis iusnaturalistas, en especial de las tesis hobbesianas ${ }^{8}$, es decir, aquel espacio anómico donde el hombre aparece como un lobo para el hombre.

Mi intención entonces es la de apelar al concepto de lo político - esbozado por Schmitt—, es decir, la distinción entre amigo y enemigo, a fin de evaluar la posibilidad de la flexibilización de la soberanía en los actuales momentos en donde como señalaba se produce una incesante amenaza para la supervivencia de distintas unidades políticas ${ }^{9}$, lo que trae consigo la inevitable crisis del Estado moderno y la aparición de conflictos de nuevo cuño, pues, la tradicional guerra entre Estados va cediendo su lugar al conflicto entre Estados contra grupos partisanos, delincuentes o terroristas y esto obliga entonces a un replanteamiento no solo de la guerra contemporánea

5 Jakobs, Günther y Manuel Cancio Melia. Derecho Penal del enemigo. Madrid: Civitas, 2003.

6 Decía Schmitt: «Como europeos de viejas tradiciones hemos de tener cuidado en no recaer en las ideas clásicas de guerra y paz», Schmitt, Carl. Teoría del partisano. Madrid: Instituto de Estudios Políticos, 1966, p. 84. Evidentemente, de aquí se desprende entonces algo que parece percibir Schmitt en sus últimos trabajos, la crisis del Estado moderno, y la consiguiente variación en la forma de la guerra contemporánea que ya no sería estrictamente la guerra de un Estado contra otro Estado. Ver respecto a esto el texto del profesor colombiano Jorge Giraldo, «Acerca de la concepción partisana de la guerra» en Carl Schmitt: Derecho, política y grandes espacios, GIRALDO, Jorge y Jerónimo Molina (editores). Bogotá: Fondo editorial de la Universidad EAFIT, Sociedad de Estudios Políticos de la Región de Murcia, 2008.

7 Schmitt, Carl. El concepto de lo político, p. 40. También ver de Portinaro, Pier Paolo. Estado, Buenos Aires: Nueva visión, 2003, p. 21.

8 Hoвbes, Thomas. Leviathan, Libro I, cap. XIII. London: Penguin, 1985

9 Aquí empleo el concepto de unidad política que usa Schmitt, en el sentido que es la unidad política lo que define la esencia de lo político y esta puede tomar distintos nombres o facetas a lo largo de la historia, puede ser la Polis en el mundo antiguo o puede ser el Estado en el mundo moderno. Cfr. El concepto de lo político. 
(y para eso están los estrategas de la guerra) sino también del derecho internacional y el orden jurídico.

En este sentido, es absolutamente válido afirmar que nuestras instituciones jurídicas aun parecen demasiado atadas al pasado que corresponde a la etapa más fecunda de la modernidad en la cual parecía que todo el mundo se encontraba perfectamente delimitado y todo muy bien organizado, es decir, una modernidad en donde la presencia del viejo nomos se dejaba aun sentir con fuerza ${ }^{10}$. Sin duda, hoy por hoy el Estado se enfrenta a su propio alter ego: «la anomia» o el «anomos» aunque lamentablemente este no parece percatarse de esta situación pues aun pretende actuar bajo el imperio de la ley y la soberanía clásica como en los años modernos aunque en estas circunstancias poco pueden hacer para preservarlo de las amenazas que ya no solo son contra el mismo Estado sino contra la propia unidad política que la antecede lo cual sería ciertamente muchísimo más grave.

\section{El Estado y la soberanía moderna}

Sabemos por historia que el Estado surge a partir de la superación de las guerras religiosas de los siglos XVI y XVII ${ }^{11}$ reemplazando así al viejo sistema imperial que había perdido su principal soporte, a saber, la religión católica, y hasta el momento sigue siendo aun válida la definición planteada por Max Weber en Economía y sociedad: «Se debe entender por Estado una empresa institucional de carácter político, en la que - y en la medida en que- el aparato administrativo plantea con éxito la pretensión del monopolio de la coerción física legítima, en vista de la actuación de los or-

10 Aquí estoy siguiendo básicamente la tesis planteada por el filósofo político Leo Strauss, especialmente en su conocido texto "The Three Waves of Modernity», STRAuss, Leo. An Introduction to Political Philosophy, ten essays by Leo Strauss. Detroit: Wayne State University Press, 1989, editado por Hilail Hildin. En dicho trabajo, el profesor Strauss trata de mostrar cómo es que la modernidad en realidad se da a partir del rechazo al pensamiento político antiguo por lo tanto en una primera etapa esta modernidad tiene que mostrar muchas de las características de la filosofía clásica pero a medida que va avanzando se va alejando de esta hasta llegar a una etapa donde la razón y la voluntad se disipan produciéndose entonces la tercera ola de la modernidad, a saber, el nihilismo.

11 Desde el momento en el cual las diferencias entre los individuos causada por la polarización religiosa se termina con la Implantación de un ley general que los iguala a todos ahora como súbditos del Estado moderno. Cfr. SkInNer, Quentin. The Foundations of Modern Political Thought. Cambridge: Cambridge University Press, 1978. 
denamientos» ${ }^{12}$. Evidentemente, tal control está garantizado dentro de un territorio determinado y es también legitimado por la misma población ${ }^{13}$. En este sentido, resulta crucial el concepto de soberanía entendido como «el poder perpetuo y absoluto de la República» ${ }^{14}$ que permite entonces a aquel o aquellos que detentan esa soberanía (léase al soberano) tener un control sobre sus súbditos y sobre el espacio en el que se encuentran sin que esta capacidad pueda ser desafiada por ningún otro poder existente (sino dejaría de ser un poder soberano).

Sin embargo, el concepto de soberanía puede ser más complejo de lo que parece por lo que durante la historia moderna se ha podido emplear dicho término de diversas maneras como lo señala el profesor Stephen Krasner:

El concepto de soberanía se ha usado en cuatro maneras diferentes: como soberanía legal internacional, como soberanía westfaliana, como soberanía interna y como soberanía interdependiente. La soberanía legal internacional hace referencias a aquellas prácticas que se relacionan con el reconocimiento mutuo, por lo general entre entidades territoriales que poseen independencia jurídica formal. La soberanía westfaliana trata de aquellas organizaciones políticas basadas en la exclusión de protagonistas externos en las estructuras de autoridad de un territorio dado. La soberanía interna se refiere a la organización formal de la autoridad política dentro del Estado y a la capacidad de las autoridades públicas para ejercer un control efectivo dentro de las fronteras del propio Estado. Por último, la soberanía interdependiente se relaciona con la capacidad de las autoridades públicas de regular el flujo de informaciones, ideas, bienes, gentes, sustancias contaminantes o capitales a través de las fronteras del Estado en cuestión ${ }^{15}$.

De esta manera, tanto la soberanía legal internacional como la de Westfalia no se vinculan con el tema del control (si con la autoridad y la legitimación) mientras que la soberanía interna si implica autoridad y control al interior del Estado y la soberanía interdependientes solamente se relaciona

12 Citado por Portinaro, Pier Paolo. Estado. Loc. cit., p. 36.

13 Aquí recordamos nuevamente la idea de dominación sugerida por Weber, a través de la cual el poder se puede prolongar en el tiempo e institucionalizar, siendo estas formas de dominación tres, la legal-racional, (la típicamente moderna) la tradicional y la carismática.

14 Bodin, Jean. Los seis libros de la República. Madrid: Aguilar, 1973, p. 46.

15 KRASNER, Stephen D. Soberanía, hipocresía organizada. Barcelona: Paidós, 2001, p. 14. 
con el control (no con la autoridad), es decir, con la capacidad que posee el Estado para supervisar todos los movimientos que se dan dentro de sus fronteras ${ }^{16}$.

Estas formas de soberanía destacada por Krasner en realidad nos llevan necesariamente a definiciones de carácter minimalista y maximalista del concepto de Estado, siendo las definiciones maximalistas aquellas que se centran en el concepto del control sobre el territorio y la posibilidad del Estado para evitar por ejemplo que circulen bienes que este no desea que lo hagan (incluyendo como dijimos ideas, sustancias, información etcétera).

Ahora bien, lo interesante es que un Estado no necesariamente tiene que tener las cuatro formas de soberanía pues podría darse el caso de que goce del reconocimiento internacional como Estado soberano pero no esté en condiciones de manejar y controlar todo su territorio. En este sentido, se entiende que cuanto más fuerte sea un Estado más posibilidades tendrá de ser soberano en todo los sentidos en cambio que la debilidad del Estado lo llevaría solamente a exhibir aquellas características minimalistas.

Esto último no es algo extraño y si bien es cierto puede señalarse habitualmente que esta sería la condición de muchos Estados en África, por ejemplo, no sería tampoco raro sostener que también muchos países en América Latina pueden gozar de muchas de las formas de soberanía minimalista ya indicadas también en la medida que en muchos lugares remotos de sus territorios no se percibe necesariamente control o supervisión estatal y parecen más bien ser tierra de nadie ${ }^{17}$.

Evidentemente, el concepto de Estado nació junto con el moderno concepto de autonomía individual por lo que no sería difícil el entablar una relación entre la noción de sujeto moderno y la de Estado soberano. En principio, sabemos que existen dos importantes principios jurídicos en el derecho internacional público, el principio de autodeterminación y el principio de no intervención, el primero ligado a la conocida noción de libertad positiva que implica la capacidad de autogobierno y el que el Estado

\footnotetext{
Ib.

17 Justamente este será el caso según sostendré al final del problema entre Colombia y Ecuador que se origina precisamente por esta debilidad de un Estado (Ecuador) al no poder ejercer el control sobre su territorio y que esto facilitaría el tránsito de indeseables en dicho espacio generando una amenaza para otros Estados.
} 
pueda determinar por si mismo sus fines y propósitos y el segundo vinculado más a la idea de no interferencia, es decir, a que ningún Estado pueda intervenir en las elecciones de otro o tratar de limitar sus políticas ${ }^{18}$.

Si es tan fácil asociar estos términos con los dos conceptos de libertad que se refieren específicamente a la autonomía individual entonces no parece descabellado plantear la analogía entre la autonomía individual y la autonomía colectiva (la del Estado) y de hecho podemos encontrar una serie de autores que a lo largo de la historia han planteado la viabilidad de tal analogía:

La analogía entre persona y Estado se ha utilizado reiteradamente para analizar las relaciones internacionales: desde la comparación del sistema internacional con un estado de naturaleza hobbesiana (sostenida ya por Wolff y en la actualidad, entre otros, por Marshall Cohen), hasta la adopción de un enfoque moral interpersonal para inferir desde allí principios de moralidad universal que deberían regir las relaciones entre los Estados (véase por ejemplo, Elfstrom ${ }^{19}$ ).

Asimismo, un académico tan conocido como Michael Walzer ${ }^{20}$ adopta esta analogía tomada en su caso del conocido filósofo liberal John Stuart Mill quien siempre barajó tal posibilidad: «debemos de tratar a los Estados como comunidades autodeterminadas, —arguye él— aun así sus acuerdos políticos internos no se hagan en libertad o los ciudadanos no escojan libremente a sus autoridades o discutan abiertamente las políticas llevadas a cabo en su nombre» ${ }^{21}$.

Así pues, si bien puede ser discutible el saber quien es el que ejerce la libertad, el pueblo, los individuos, el gobierno, etcétera, lo claro es que si resulta válida la analogía y que se ha empleado repetidas veces en el terreno de las relaciones internacionales y el derecho internacional público ${ }^{22}$. Sin embargo, hay que destacar que los argumentos de Mill y los de Walzer se dan con el propósito de rechazar cualquier forma de intervención en la

18 Sobre la libertad negativa y positiva ver el texto de BERLIN, Isaiah. «Dos conceptos de libertad». En Four Essays on Liberty. Oxford: Oxford University Press, 1969.

19 Garzón Valdés, Ernesto. «Intervención y paternalismo». En Instituciones suicidas. Estudios de ética y política. México: Editorial Paidós Mexicana y Universidad Autónoma de México, 2000, p. 162.

20 Walzer, Michael. Just and Unjust Wars. New York: Basic Books, 1992.

21 Ib., p. 87.

22 Garzón Valdés, Ernesto. Ob. cit., pp. 164-165. 
soberanía estatal aun así se trate para el bien del propio Estado ${ }^{23}$. En este sentido, la posición del profesor Garzón Valdés, en su artículo citado, es sin embargo discrepante respecto a ellos pues él si considera que pueda haber situaciones en las cuales las intervenciones se pueden justificar - por ejemplo en caso de una flagrante violación a los derechos humanos- atendiendo entonces a una forma de paternalismo jurídico:

Por el contrario, sea que se trate de un gobierno propio o de uno extranjero, la intervención para ayudar a que un pueblo derroque a una tiranía puede no solo estar justificada sino incluso constituir un acto debido [...]. Pero en el caso 6 no se agota en el ejemplo de las guerras de liberación; en el caben todas las situaciones en que se violan derechos humanos básicos, es decir, aquellos que son un medio necesario para la satisfacción de todos los derechos ${ }^{24}$.

Hasta este momento entonces podemos concluir con lo siguiente: primero, es válido el poder plantear la analogía entre el sujeto autónomo y la soberanía estatal, en segundo lugar, es posible que se discuta la posibilidad de desafiar en algunos casos principios como el de «no intervención» como lo demuestra el profesor Garzón Valdés, aunque en su caso particular esto se haga a favor de la defensa de su famoso «coto vedado» de los derechos fundamentales, en tercer lugar, hemos visto también que la soberanía posee una variada graduación y que solamente unos cuantos Estados en el planeta podrían jactarse de contar con todas las formas de soberanía existentes, y en cuarto lugar, reconocemos también que nos encontramos en un período de gran incertidumbre en el cual las definiciones clásicas planteadas a inicios de la modernidad (soberanía, Estado, autonomía, etcétera) pueden y tienen que ser replanteados a la luz de la realidad.

En la siguiente parte de este texto voy a tratar de justificar las acciones militares emprendidas por el gobierno colombiano en territorio ecuatoriano como una forma de paternalismo jurídico que además se legitima en la necesidad de preservar las unidades políticas tanto de Colombia como del mismo Ecuador.

$\begin{array}{ll}23 & \text { Ib., p. } 168 . \\ 24 & \text { lb., p. } 172 .\end{array}$ 


\section{La flexibilización de la soberanía en los tiempos de guerra}

Efectivamente, al iniciar este texto afirme que estamos en una época en la cual los conflictos se presentan en distintas formas y donde ya no tiene mucho sentido pensar en la guerra como una lucha entre Estados. Lo que vemos en la actualidad es más bien la presencia de grupos armados muchas veces unidos a bandas de delincuentes (narcotraficantes por ejemplo) quienes tratan de usar a los Estados como instrumentos a sus servicios bajo la vieja idea de que están luchando contra alguna tiranía o régimen opresor, esta tesis que puede sostenerse en la mayoría de los casos sirve sin embargo para «legitimar» una lucha y para poner en aprietos a las autoridades de los gobiernos de diversos Estados que tratan de salvaguardar la unidad política (el nomos).

Ciertamente, he estado enfatizando reiteradamente el concepto de unidad política que lo tomo como dije de la tradición schmittiana y que antecede en realidad a cualquier organización o estructura política como la ciudad antigua, el Imperio y por supuesto el Estado. Ahora bien, tendría sentido el preguntarse del porque de la importancia de la unidad política y ante una pregunta como esa pueden ensayarse también múltiples respuestas pero creo que las más importantes y las que podrían considerarse un buen argumento están por el lado de lo valioso que resulta para un individuo el pertenecer a una unidad política que le procure de lo esencial para vivir y para poder aspirar a una vida buena.

A menudo resulta olvidado el hecho de que nosotros apreciamos al nomos y el orden que este funda no solo porque este orden nos protege sino porque podría ser indispensable para que cada uno de nosotros pueda tener y pueda desarrollar un plan o un proyecto de vida, es decir, que en último término el valor de la unidad política reside en la protección que este le da a valores modernos tan significativos como la autonomía personal por ejemplo, y no podemos dejar de mencionar también que finalmente el mismo concepto de derecho moderno (véase inclusive a los autores positivistas como Kelsen o Hart) estaba dirigido a asegurar la supervivencia, la paz, y todo ello con el propósito de asegurar la viabilidad de una sociedad de seres autónomos ${ }^{25}$.

25 Esto es por ejemplo lo que encontramos en el denominado mínimo moral del derecho según H.L.A HART. Cfr. HART, H.L.A. El concepto del Derecho. Buenos Aires: AbeledoPerrot, 2007, pp. 239-254. 
Por todas estas cosas entonces es que el luchar por preservar la unidad política tiene sentido y resulta entonces una tarea encomiable, y por eso mismo es que debemos de procurarnos de todos los medios que tenemos a nuestra alcance para lograr este propósito a pesar de las amenazas que se ciernen sobre esta. Dichas amenazas pueden responder a distintos propósitos aunque en la dimensión del realismo político (en el que me muevo dicho sea de paso) no es tan importante el indagar sobre los fines o las intenciones sino simplemente lo importante es el poder identificar a la amenaza y ver la manera de neutralizarla.

Es en este contexto entonces que elegí la reciente controversia entre Colombia y Ecuador respecto al caso de la incursión de las Fuerzas Armadas Revolucionarias de Colombia (FARC) a fin de evaluar la justificación de tal acción a pesar de que pueda ser considerada una violación a los principios fundamentales del derecho internacional como el de no intervención todo esto dentro del marco tradicional del Estado moderno.

Para lograr este objetivo de justificación como indique, voy a apelar a la conocida analogía entre el Estado soberano y el sujeto autónomo y con esto valerme de una fundamentación basada en la figura del paternalismo jurídico y espero aun reforzar mi punto de vista apelando también a las formas de soberanía destacadas por Krasner con el objeto de demostrar que existen muchos Estados (como el Ecuador por ejemplo) que no puede ejercer una soberanía plena sobre su territorio y por lo tanto no podría presumir el hecho de la violación de parte de su territorio — que aparentemente no controla - por parte de otro Estado cuando vemos que fuerzas irregulares como las FARC lo violan a su antojo.

\section{El paternalismo jurídico}

Ciertamente, el concepto de paternalismo jurídico es un término muy conocido dentro del campo de la teoría legal desde hace mucho tiempo y hay referencias a él desde los textos clásicos del liberalismo como el ensayo de John Stuart Mill «On Liberty» ${ }^{26}$ (Sobre la libertad) en el siglo XIX hasta en

26 MiLL, John Stuart. Sobre la Libertad. Madrid: Alianza, 1981. 
los trabajos de los teóricos del derecho más contemporáneos como Carlos Santiago Nino ${ }^{27}$ o Ernesto Garzón Valdés ${ }^{28}$.

Así dice Mill en un muy citado párrafo sobre la restricción a la libertad:

Este principio consiste en afirmar que el único fin por el cual es justificable que la humanidad, individual o colectivamente, se entremeta en la libertad de acción de uno cualquiera de sus miembros es la propia protección. Que la única finalidad por la cual el poder puede, con pleno derecho, ser ejercido sobre un miembro de una comunidad civilizada contra su voluntad, es evitar que se perjudique a los demás. Su propio bien, físico o moral no es justificación suficiente. Nadie puede ser obligado justificadamente a realizar o no realizar determinados actos, porque eso fuera mejor para él, porque le haría feliz, porque, en opinión de los demás, hacerlo sería más acertado o más justo ${ }^{29}$.

Como señala Ernesto Garzón Valdés podríamos llamar paternalismo a aquella restricción coactiva en la libertad de elección de una persona destinada a evitar que se infrinja un daño a sí misma ${ }^{30}$, a su vez para Carlos Santiago Nino el paternalismo consistiría en la imposición a los individuos de conductas que son adecuadas para que puedan satisfacer sus preferencias personales y sus planes de vida elegidos libremente ${ }^{31}$. En este sentido, se podría incluir por ejemplo el que se prohíba bañarse en una playa porque hay tiburones en los alrededores, en la vacunación obligatoria, el empleo de casco para manejar motocicleta, en la obligatoriedad de la educación primaria entre muchas otras. Sin embargo, hay que tener cuidado en no confundir el paternalismo con lo que significa el daño a tercero (que sería además la única situación en la que para Mill se justificaría la restricción individual) y a su vez también lo que sería el perfeccionismo que estaría más bien referido a orientar las elecciones de los individuos hacia planes u opciones de vida más deseables o considerados como mejores ${ }^{32}$.

27 Nino, Carlos Santiago. Ética y Derechos Humanos, Buenos Aires: Astrea, 2005.

28 Garzón Valdés, Ernesto. «¿Es éticamente justificable el paternalismo jurídico?». En Tolerancia, dignidad y democracia. Lima: Universidad Inca Garcilaso de la Vega, 2006, también en el ya citado artículo «Intervención y paternalismo».

29 MiLL, John Stuart. Sobre la Libertad, p. 65.

30 GarZón Valdés, Ernesto. "¿Es éticamente justificable el paternalismo jurídico?», p. 287.

31 NinO, Carlos Santiago. Ob. cit., p. 414.

32 Respecto a este tema se puede ver mi texto, HeRnando Nieto, Eduardo. «Constitución Sustantiva: autonomía, perfeccionismo y la legalidad neutral». Pensamiento Constitucional, Lima: PUCP, Año VII, No 7, 2000. También en el mismo trabajo de Carlos Santiago Nino, 
Sin embargo, como hemos leído en el texto de John Stuart Mill toda limitación que no se trate de prevenir un daño a otro sería inaceptable pues se estaría reduciendo arbitrariamente la libertad de elección personal, de hecho, como crítica al paternalismo jurídico se podría indicar los siguientes argumentos:

- El argumento utilitarista

- El argumento del respeto a la autonomía

- El argumento a la violación al principio de igualdad ${ }^{33}$

En el primer caso, se trata precisamente de la tesis de Mill basada en la idea de que nadie puede ser mejor juez que uno mismo y nadie mejor que uno para saber si algo afecta o no a sus intereses. La idea de que alguien puede conocer las preferencias de otros se basa muchas veces en presunciones generales mas no en verdades objetivas, además la sociedad saldría ganando — dice- si es que se permite que cada quien viva como mejor le parece ${ }^{34}$.

Por su parte en relación con el argumento del respeto a la autonomía Garzón Valdés cita en primer término a Hayek: «La intervención paternalista del Estado destruye la autonomía individual, se dice, y conduce fatalmente a la servidumbre» ${ }^{35}$. Sin embargo, como también agrega bien el profesor Garzón Valdés, esta claro que el concepto autonomía tiene diversos significados, pues esta puede ser entendida como oportunidad, como capacidad de elección y como conformidad con la ley moral ${ }^{36}$. Yo mismo señale en otro artículo que la autonomía podía entenderse en términos de elección, de elección racional y de autorrealización ${ }^{37}$. Es decir, que habría

Ética y derechos humanos, se desarrolla el concepto del perfeccionismo aunque desde un punto de vista bastante crítico.

33 Garzón Valdés, Ernesto. «¿Es éticamente justificable el paternalismo jurídico?». Loc. cit., p. 290. Estas críticas obviamente están extraídas del texto de John Stuart Mill, Sobre la libertad.

lb., pp. 291-292.

35 Ib., p. 293.

$36 \quad$ lb., pp. 294-295.

37 «Por ejemplo, muy bien podría añadirse al término elección, el agregado de racional, teniéndose entonces una fórmula de autonomía en términos de «elección racional». Ahora bien tal añadido implicaría más que un matiz un cambio sustantivo puesto que se trataría evidentemente de una restricción que tamizaría el deseo por medio de la razón y en tal situación, la autonomía solo podría manifestarse al efectuarse exclusivamente elecciones racionales y no cualquier tipo de elección a secas». HeRnANDO Nieto, Eduardo. «Constitución sustantiva: autonomía, perfeccionismo y la legalidad neutral», p. 90. 
que evaluar en cada caso que es lo que significa realmente una afectación a la autonomía lo cual no permitiría afirmar que el paternalismo atenta contra la autonomía.

Finalmente, está el argumento de la violación del principio de igualdad que asegura que cualquier medida paternalista implicaría una violación a un principio básico de la democracia como el de la igualdad, sin embargo, existen una serie de ejemplos que rechazarían tal aserto como en los casos en los cuales se obliga a una persona a dar parte de su sueldo a fin de contar con un fondo de jubilación. En este caso, parece inexacto el considerar que tal medida afecta el principio de igualdad cuando más bien parecería todo lo contrario ya que esta medida al final lograría que las personas una vez que se jubilen no sean tan vulnerables.

Ciertamente, las críticas y cuestionamientos lanzados contra el paternalismo jurídico parecen no ser suficientes como para descartarlo y de hecho el discurso jurídico liberal puede aceptar en muchas ocasiones conductas paternalistas como lo demuestran dos autores liberales como Garzón Valdés o Nino, quienes han citado muchísimos ejemplos al respecto.

Por ejemplo, una de las razones que puede ser esgrimida es el caso de la debilidad de voluntad — desafiando así la tesis de Mill de que todo individuo sabe reconocer lo que es bueno para uno- por parte del afectado (un alcohólico), pero también es posible encontrar situaciones en las cuales se ignora cual es la naturaleza del peligro (alguien quiere bañarse en un río y no sabe que esta infectado de pirañas) o de alguien que no cuenta con todas sus facultades básicas, etcétera, a quien se encuentra en una situación como esta es posible de ser tildado de «Incompetente Básico» encontrándose como se dice — Garzón Valdés- en una situación de desigualdad negativa, que puede ser temporaria, permanente, focalizada o tota ${ }^{38}$, empero, también es cierto que él considera algunos casos en los cuales no se justificaría el paternalismo como en el caso de alguien con competencia básica que quiere ocasionarse un daño a sí mismo o privarse la vida o cuando alguna persona también competente opta por correr un riesgo elevado en pro de su felicidad o placer (un enfermo de enfisema que insiste en seguir

38 GaRZÓn Valdés, Ernesto. «¿Es éticamente justificable el paternalismo jurídico?», pp. 300301. 
fumando) o finalmente cuando alguien también competente arriesga su vida por los demás ${ }^{39}$.

Es verdad, que a nivel de discusión académica el concepto de «incompetente básico» ha sido objeto de diversas críticas (por ejemplo por su vaguedad) y pueden ser discutibles también algunas de sus excepciones, no obstante ello, suscribo básicamente el fondo de su argumentación y por lo tanto considero que es aceptable la legitimidad y la racionalidad de determinadas restricciones a ciertas formas de elección siempre y cuando esta restricción contribuya a afirmar a futuro la capacidad de ser un sujeto de elección ${ }^{40}$.

\section{Flexibilizando el nomos: el caso Colombia-Ecuador}

Los hechos según lo describió cierta prensa favorable a la posición ecuatoriana:

En horas de la madrugada del día primero de marzo, fuerzas armadas colombianas invadieron el territorio ecuatoriano para concretar el asesinato del líder número dos de las Fuerzas Armadas Revolucionarias de Colombia (FARC), Raúl Reyes, y otros miembros de este ejército.

- En un primer comunicado, el Gobierno de Colombia señaló que la muerte de Raúl Reyes y otros insurgentes había sido en combate, versión que fue desmentida por el presidente de Ecuador, Rafael Correa, quien después de las investigaciones de la Fuerza Armada de su país confirmó que fue una masacre, puesto que los guerrilleros dormían al momento del bombardeo. De hecho, todos los fallecidos estaban en ropa interior. Solo 3 mujeres permanecen con vida y son atendidas en centros médicos de Ecuador.

- El campamento de las FARC, ubicado en la frontera con Ecuador, quedó totalmente devastado. El Gobierno colombiano violó al menos 10 kilómetros del espacio aéreo del vecino país para llevar a cabo el bombardeo y posteriormente entró (el Ejército) al país para retirar los cadáveres de Reyes y de Guillermo Enrique Torres, alias 'Julián Conrado', otro líder insurgente. Los demás fallecidos y las mujeres heridas, que se encontraban en paños menores, quedaron a su suerte.

39 Ib., p. 305.

40 Pienso por ejemplo en el caso de la obligatoriedad del uso del cinturón de seguridad al momento de manejar un vehículo, a pesar de que haya quienes consideren que en verano puede ser difícil su uso. 
Como ya acotamos, el caso del bombardeo al campamento de las FARC generó una serie de reacciones contrarias al Estado colombiano y en particular al régimen del presidente Uribe que fue acusado de violar flagrantemente el espacio aéreo y terrestre del Ecuador, obviamente sin su consentimiento. Esto sería inaceptable desde la óptica ecuatoriana e inclusive generó una tensión en la que la palabra guerra no sonaba tan lejana.

Sin embargo, mi intención es tratar de dar una justificación de esta decisión y que se enmarca básicamente en tres puntos de acuerdo al argumento de mi texto:

i. La variación del concepto de soberanía en la actualidad tanto por la situación de emergencia global como por la variable económica

ii. La clase de soberanía que ejercería realmente el Estado ecuatoriano

iii. La posibilidad de la analogía entre la autonomía individual y la autonomía estatal a fin de permitir la inclusión de la figura del paternalismo jurídico y justificar la acción colombiana

Como había anotado al inicio del texto, estamos viviendo tiempos difíciles en materia de seguridad y esto explicaría por ejemplo el auge de la teoría de la excepción (Schmitt) o el derecho penal del enemigo (Jakobs). Esto es un hecho, así como también es un hecho la manera como ha ido cambiando la forma de los conflictos o de la guerra contemporánea que ya no se caracteriza por la lucha entre Estados sino por la presencia de grupos partisanos o terroristas que se enfrentan a distintas unidades políticas colocando además en serios aprietos al mismo derecho internacional ${ }^{41}$.

Pero, junto con el fenómeno de la violencia también es cierto que la economía mundial ha venido desafiando desde hace muchos años la idea clásica de la soberanía, en este sentido, el llamado globalismo o globalización económica ha servido para debilitar hasta cierto punto las barreras y controles Estatales en aras de lograr un comercio más eficiente ${ }^{42}$.

41 MASCHKE, Günter. «La autodestrucción del derecho internacional». Empresas Políticas, Año V, No 7, Murcia, Sociedad de Estudios Políticos de la Región de Murcia, 2006. Recomendamos la lectura de esta revista que se centra en el estudio del realismo europeo (Schmitt, Freund, Aron, etcétera) y tiene mucha información en torno al tema del conflicto contemporáneo. Igualmente sobre el particular cfr. de GIRALDO, J. El rastro de Caín. Guerra, paz y guerra civil. Bogotá: Foro Nacional por Colombia, 2001.

42 Dice el sociólogo Ulrich Beck al respecto: «Por globalismo entiendo la concepción según la cual el mercado mundial desaloja o sustituye al quehacer político; es decir, la 
Todo esto junto con los discursos de la llamada postmodernidad que relativizan el concepto de $\operatorname{Nomos}^{43}$, hacen que sea inevitable juzgar este caso bajo otra óptica ya que la defensa que plantea el Estado Ecuatoriano respecto a la incursión parecería hacerse en el contexto del siglo XIX y sin tomar en cuenta todos estos hechos descritos. Finalmente, también parece contradictorio como es que en muchos casos quienes aun defienden la concepción decimonónica de soberanía no tienen la misma vehemencia para objetar la globalización económica.

Respecto a este último punto quiero afirmar también como es que de acuerdo a las distintas concepciones de soberanía que se manejan (Krasner), Ecuador no podría sostener que es plenamente soberano pues quizá en el planeta serían muy pocos los Estados que puedan mantener las cuatro formas de soberanía, por los hechos narrados por la misma prensa internacional se desprende que los efectivos de las FARC estuvieron un buen tiempo en territorio ecuatoriano, es decir, ellos podían entrar y salir del territorio del Ecuador sin que aparentemente sean detectados, esto serviría para afirmar entonces que Ecuador carece de soberanía interna y de soberanía interdependiente. Entonces, ¿qué significaría realmente afirmar que se ha violado su soberanía?

Finalmente, está el tema de la analogía, como ya indique, suscribo la tesis de la vinculación entre la autonomía individual y la soberanía estatal, en este caso, como ya se ha visto, sería posible intervenir y limitar la libertad de un Estado si es que se trata de lograr un bien para él. En este caso, las FARC como grupo terrorista y vinculado a una serie de delitos como el narcotráfico y el secuestro es una amenaza para nuestra región y en este caso concreto también sería un peligro para el Ecuador en caso de

ideología del dominio del mercado mundial o la ideología del liberalismo. Esta procede de manera monocausal y economicista y reduce la pluridimensionalidad de la globalización a una sola dimensión, la económica [...]». BECK, Ulrich. ¿Qué es la globalización? Falacias del globalismo, respuestas a la globalización. Barcelona: Paidós, 1998, p. 27. Ciertamente, sobre este tema hay una profusa bibliografía y entre los textos más clásicos se puede citar, Ohmae, Kenichi. El fin del estado-nación. Santiago de Chile: Andrés Bello, 1997; Zolo, Danilo. Cosmópolis, perspectiva y riesgo del gobierno mundial. Barcelona: Paidós, 2000; HeLd, David y Anthony McGrew. Globalización / Antiglobalización, sobre la reconstrucción del orden mundial. Barcelona: Paidós, 2003.

43 Hernando Nieto, Eduardo. "Teología política y el problema de la línea». Empresas Políticas, Año III, № 4. Murcia, Sociedad de Estudios Políticos de la Región de Murcia, 2004. 
que puedan buscar su expansión. Si bien es verdad, que es posible que el gobierno del Ecuador pueda mostrar cierta simpatía ideológica con las FARC, la acción militar colombiana se oriento más bien a tratar de defender la unidad política del Ecuador ${ }^{44}$ y por tratarse de una medida que busca combatir este peligro para beneficio del mismo pueblo ecuatoriano podría ser entonces justificable. En conclusión, la actitud del gobierno del Ecuador parecería enmarcarse dentro del concepto de «incompetencia básica» y por ello permitiría lícitamente intervenciones como la comentada, la misma que a todas luces no tuvo ningún propósito de conquista o mucho menos de derrocar al gobierno de turno ecuatoriano.

44 Paradójicamente la incursión de la Fuerza Aérea Colombiana no fue hecha para buscar atacar al pueblo ecuatoriano o despojarlos de su territorio sino más bien para liberarlos de un peligro que podría minar a futuro su propia unidad y limitar ahora sí de manera concreta su autonomía. 